\title{
An Assessment of Nutrition Practices and Attitudes in Family Child-Care Homes: Implications for Policy Implementation
}

\author{
Alison Tovar, PhD, MPH; Patricia Risica, DrPH; Noereem Mena, MS, RD; \\ Eliza Lawson, MPH; Angela Ankoma, MSW; Kim M. Gans, PhD
}

\begin{abstract}
Suggested citation for this article: Tovar A, Risica P, Mena N, Lawson E, Ankoma A, Gans KM. An Assessment of Nutrition Practices and Attitudes in Family Child-Care Homes: Implications for Policy Implementation. Prev Chronic Dis 2015;12:140587. DOI: http://dx.doi.org/10.5888/pcd12.140587.
\end{abstract}

\section{PEER REVIEWED}

\section{Abstract}

\section{Introduction}

Family child-care homes (FCCHs) provide care and nutrition for millions of US children, including $28 \%$ in Rhode Island. New proposed regulations for FCCHs in Rhode Island require competencies and knowledge in nutrition. We explored nutrition-related practices and attitudes of FCCH providers in Rhode Island and assessed whether these differed by provider ethnicity or socioeconomic status of the enrolled children.

\section{Methods}

Of 536 licensed FCCHs in Rhode Island, 105 randomly selected FCCH providers completed a survey about provider nutrition attitudes and practices, demographics of providers, and characteristics of the $\mathrm{FCCH}$, including participation in the federal Child and Adult Care Food Program (CACFP). No differences between CACFP and non-CACFP participants were found; responses were compared by provider ethnicity using $\chi^{2}$ tests and multivariate models.

\section{Results}

Nearly $70 \%$ of FCCHs reported receiving nutrition training only 0 to 3 times during the past 3 years; however, more than $60 \%$ found these trainings to be very helpful. More Hispanic than non-Hispanic providers strongly agreed to sitting with children during meals, encouraging children to finish their plate, and being in- volved with parents on the topics of healthy eating and weight. These differences persisted in multivariate models.

\section{Discussion}

Although some positive practices are in place in Rhode Island FC$\mathrm{CHs}$, there is room for improvement. State licensing requirements provide a foundation for achieving better nutrition environments in FCCHs, but successful implementation is key to translating policies into real changes. FCCH providers need culturally and linguistically appropriate nutrition-related training.

\section{Introduction}

Close to one-third of US children aged 2 to 5 years are overweight or obese. Clear disparities are observed by ethnicity; $17 \%$ of Hispanic children in this age group are obese compared with $3.5 \%$ of their non-Hispanic white counterparts (1). Contributing to the obesity epidemic are unhealthy eating patterns, including high consumption of energy-dense snack foods and low consumption of fruits and vegetables (2). These patterns are troubling, given that early childhood is a critical period during which dietary intake patterns and eating habits are developed (3). Although parents play a critical role in shaping children's food preferences and determining their physical and social environments, the child-care setting (nonparental care either at a center or family child-care home $[\mathrm{FCCH}]$ ) and its providers (those who care for children in childcare settings) are also important in shaping healthy behaviors. Child-care providers can affect children's healthy eating habits through appropriate feeding practices and attitudes and by influencing the access and availability of healthy foods and beverages in child-care environments (the physical and social conditions at the child-care setting) (4). Therefore, fostering effective strategies to help child-care providers establish healthy eating habits and promote healthy environments among disadvantaged populations is critical. 
Creating healthy child-care environments is of great importance, because almost $60 \%$ of children in the United States younger than 6 are enrolled in some type of nonparental care each week, and nearly $50 \%$ of enrolled children identify as Hispanic (5). Policies and regulations ensure healthy nutrition environments in childcare settings (6), and practical professional training and education of child-care providers is needed to translate policies into healthy practices. Most recent training programs and interventions to improve healthy behaviors focused on child-care centers (7); however, 2 million US children (25\%) and 21,000 Rhode Island children (28\%) in nonparental care attend an FCCH (8), a childcare setting where children are cared for by child-care providers in their homes rather than in a center. Regulations for licensed FC$\mathrm{CHs}$ are different, and in most cases less stringent, than those for free-standing child-care centers (9). Moreover, time spent in FCCH settings during infancy is associated with increased body mass index (BMI) $z$-scores at 3 years of age, and time spent in child-care centers is not (10).

In Rhode Island, recently proposed updated regulations for both child-care centers and FCCHs would require more provider knowledge and competencies, including more nutrition education. For FCCHs, these proposed regulations would include increasing the required hours of provider professional development related to the new competency requirements. These regulations are still under review; however, given that more nutrition training will likely be required, it is important to know how to tailor the content and format of these trainings so that they meet the needs of FCCH providers.

Given the lack of research on FCCHs, understanding provider's nutrition-related practices and attitudes and exploring variation across contexts is important. With this information, more appropriate trainings relevant to nutrition-related regulatory policies in FCCHs can be developed. The goal of this study was to explore nutrition-related practices and attitudes of $\mathrm{FCCH}$ providers in Rhode Island and assess whether these differed by provider ethnicity or socioeconomic status of the enrolled children.

\section{Methods}

Key informant interviews were conducted during summer 2012 with child-care stakeholders from Rhode Island, including FCCH providers and state agency representatives, to inform the development of a statewide survey with Rhode Island FCCH providers. Previous literature on similar evaluation instruments was also reviewed (11-13). On the basis of this formative research, a survey instrument was developed to administer to Rhode Island FCCH providers. The instrument contained 12 home-specific questions including the respondents' background in education and child-care and whether the center participated in the US Department of Agriculture's Child and Adult Care Food Program (CACFP), a federal program that provides reimbursement for healthful meals and snacks served to low-income children and adults, and BrightStars, the Rhode Island child-care provider quality rating system (14), both of which include nutrition standards. The survey also included 62 food or nutrition attitude or practice-related questions. Selected food questions were adapted from the California ChildCare Food Assessment's Survey of Child Care Providers of 2-5 Year Old Children (12). For the purpose of this article, we include questions relating to nutrition training, child feeding practices and attitudes, and parental involvement (Table).

We set a goal of obtaining 100 completed surveys from the 536 licensed FCCHs in Rhode Island. Because the feasibility and cost of reaching all 536 licensed FCCHs was prohibitive, we determined that reaching 100 licensed providers was an adequate number from which to draw conclusions. Calls were made to batches of 10 to 15 numbers at a time, which were called until a final disposition was determined before working on a new batch of numbers. This method ensured that all numbers received the same attention and minimized the bias from assessing only early responders. The team stopped calling new batches when the goal of 100 completed surveys was close to being reached, which happened as we completed the twelfth batch. Our sample from the 12 batches included 360 providers; 243 of these were eligible (still in business, spoke English or Spanish). FCCH providers who were reached were offered to take the survey by telephone, online, or receive it as a paper document to be returned in the mail. The study was reviewed and approved by the institutional review board at Brown University, Providence, Rhode Island.

Chi-square statistics were calculated to determine differences in reported practices and attitudes by CACFP and provider ethnicity status in separate analyses. Few of the items differed by CACFP status, so the multivariate analysis focused on ethnic differences. Multivariate models were constructed by using SAS version 9.3 (SAS Institute, Inc) as generalized linear models using a logit link function and indicating that the response options were multinomial. Because of small numbers in some cells, response options were collapsed for some variables (Table). Final models included CACFP status as an adjustment for both program participation and as a proxy indicator of socioeconomic status of the provider and children being served.

\section{Results}

A total of $105 \mathrm{FCCH}$ providers, representing $43 \%$ of the eligible FCCHs called, completed a survey in either Spanish (35\%) or English $(65 \%)$. Ineligible homes $(33 \%$ of the overall sample

\footnotetext{
The opinions expressed by authors contributing to this journal do not necessarily reflect the opinions of the U.S. Department of Health and Human Services, the Public Health Service, the Centers for Disease Control and Prevention, or the authors' affiliated institutions.
} 
called) were those in which the telephone number was not working or the home was no longer a child-care home provider. Of the responding providers, 39\% identified as Hispanic, $43 \%$ as nonHispanic white, and 3\% as non-Hispanic black. Providers estimated the families of children in their care as $43 \%$ Hispanic, $46 \%$ non-Hispanic white, 7\% non-Hispanic black, and 2\% Asian. Half $(50 \%)$ of responding providers indicated that they participated in CACFP, and 34\% reported participating in BrightStars.

Nearly $70 \%$ of providers reported receiving nutrition training only 0 to 3 times during the past 3 years; however, more than $60 \%$ of them found these trainings to be very helpful. They also reported that it would be very helpful to have more nutrition training specific for FCCHs (Table). Most providers strongly agreed that they sit with children during snacks and meals (67.3\%) and were highly motivated to serve healthy foods to children (71.8\%). Approximately three-quarters, however, agreed or strongly agreed that they encourage children to finish all the food on their plate $(74.7 \%)$. Most providers (90\%) disagreed or strongly disagreed that the children in their care were involved in nutrition-related plans and activities.

Several significant differences were observed by provider ethnicity, even after adjustment for CACFP status. Hispanic providers reported receiving more nutrition training during the past 3 years than did non-Hispanic providers (46.2\% vs $23.8 \%$ ) and were more likely to find the training very helpful (91.9\% vs $45.1 \%$ ) (Table). More Hispanic providers reported strongly agreeing to sitting with children during snacks and meals than did non-Hispanic providers $(80.0 \%$ vs $59.4 \%, P=.02)$, but more Hispanic providers also reported strongly agreeing to encourage children to finish food on their plate than did non-Hispanic providers $(80.0 \%$ vs $12.7 \%, P<$ $.001)$. Hispanic providers also reported less child involvement in nutrition-related plans and activities than did non-Hispanic providers $(56.4 \%$ vs $35.5 \%, P=.04)$ (Table).

More non-Hispanic than Hispanic providers strongly agreed or agreed with the statement that "parents say their children will eat certain foods at daycare and not at home" (88.9\% vs 61.1\%). More Hispanic than non-Hispanic providers strongly agreed with the following statements: "I believe it is important to communicate with parents/families regarding nutrition" (87.8\% vs $46.9 \%)$ and "I discuss with parents/families if lunches or snacks sent in are not healthy" (66.7\% vs 20.4\%). Hispanic FCCH providers also felt more comfortable than non-Hispanic providers in passing information on to parents and families about good nutrition practices $(70.0 \%$ vs $45.2 \%)$ and encouraging breastfeeding $(79.0 \%$ vs $59.6 \%$ ). More Hispanic than non-Hispanic providers strongly agreed that they were comfortable discussing a child's weight problem with parents or families (56.4\% vs $22.8 \%$ ) (Table).

\section{Discussion}

The goals of this study were to explore provider practices and attitudes related to nutrition in a sample of Rhode Island FCCH providers and to assess if practices differed by ethnicity of the provider. Overall, we found that positive practices were displayed related to feeding, such as sitting with the children during meals and snacks and eating the same foods as the children, which provide an opportunity to model appropriate behaviors and positive feeding practices with children (15). However, we also found providers commonly encouraged children to finish all the food on their plates, which may interfere with a child's internal cues for satiety and hunger, possibly contributing to the development of obesity (16). Controlling feeding practices are associated with the development of unhealthy eating behaviors and childhood obesity (16). Training for FCCH providers should address responsive child-feeding practices (17), including allowing children to control the amount of food they eat without pressure or control, modeling healthy eating, and serving meals family-style.

Although we hypothesized that nutrition practices may differ by CACFP program participation as a proxy for socioeconomic status, we found that this was not the case. However, provider ethnicity was a predictor of certain nutrition practices, suggesting a possible cultural influence among these providers. More Hispanic than non-Hispanic providers reported sitting with children while they ate, but Hispanic providers also reported being more likely to encourage children to finish all the food on their plate and less likely to involve children in nutrition education. Hispanic providers also reported more communication with parents about children's diet and weight. Results from several studies have shown that feeding practices differ by ethnicity (18). For example, some studies indicate that Hispanic parents are less likely to set limits around meal times compared with other racial/ethnic groups, although results are mixed (19). Although most of these studies were conducted with parents instead of child-care providers, one study found that Hispanic providers were more involved than nonHispanic providers with what the children were doing during mealtimes and exhibited more demanding practices such as making children eat all the food on their plate (20). Another study also supports our findings in that Hispanic providers (both home- and center-based) were more likely to encourage children to finish meals (21). Given that many FCCHs serve ethnic minority children and are run by ethnically diverse providers (in Rhode Island, more than $40 \%$ of FCCH providers are Spanish-speaking), these findings highlight possible cultural differences and underscore the need for policies and trainings to be culturally relevant. Our findings also indicate the importance of training non-Hispanic providers about responsive feeding, including sitting with children

The opinions expressed by authors contributing to this journal do not necessarily reflect the opinions of the U.S. Department of Health and Human Services, the Public Health Service, the Centers for Disease Control and Prevention, or the authors' affiliated institutions. 
during meals. Further research is needed to better understand providers' feeding practices and explore how continuing education and training can be delivered so that providers can learn how to improve feeding practices in culturally appropriate ways. In childcare centers, training providers in nutrition practices has improved provider knowledge, center policies, and children's diet quality and weight status $(6,22)$, but more research is needed on such interventions with FCCHs.

Our data also showed that more Hispanic providers than non-Hispanic providers felt comfortable communicating with parents about healthy foods and a healthy weight. Although evidence suggests that parents who use an FCCH appreciate a more intimate relationship with providers (20), our results suggest that in this population there are ethnic variations and that Hispanic providers may feel a closer relationship with parents. Hispanics tend to be more collectivistic, family-oriented, and focused on maintaining smooth and positive social interactions than non-Hispanic whites (23). These cultural norms may allow for a more open discussion between parents and FCCH providers about children's eating habits and weight status. Having this open line of communication is important for Hispanic parents, because they frequently do not recognize their children as overweight and may have a more favorable view of childhood obesity, which may prevent them from seeing their child's weight as problematic (24). Both Hispanic providers and parents may be less concerned about preventing childhood obesity and more concerned about their child eating enough (25). Future research should examine these issues and explore ways to facilitate better communication about nutrition between providers and parents, especially among non-Hispanic providers. A previous study found that providers reported the need for better communication and cooperation with parents (26). Prior studies have also emphasized the need to influence both the home and the child-care environment to successfully engage in obesity prevention, because children spend time in both these environments $(27,28)$. One study has shown the promise of including parents and home-based activities as part of child-care-based interventions in reducing BMI $z$-scores in young children (29). Therefore, future work should use an ecological approach when exploring the interactions between home and child-care environments and how positive obesity prevention practices and environments can be consistent across both settings.

Regardless of provider ethnicity, our findings suggest the need for effective policies and supportive trainings and resources to improve the nutrition environments of FCCHs. Many expert groups (30-32) have emphasized the establishment of quality prevention policies as a foundation for improving the food, physical activity, breastfeeding, and screen-time environments in child-care settings (33). However, creating policies alone is not enough (30). Policies are more likely to succeed with trainings and education for childcare providers (34), and few studies have documented FCCH provider training. We found that most FCCH providers do not frequently participate in nutrition training, which is similar to the findings of Trost et al who found that less than $50 \%$ of staff in FC$\mathrm{CHs}$ received annual training on nutrition (35). Although provider participation in Rhode Island FCCH trainings is low, interest is high; more than $50 \%$ of FCCH providers in this study indicated that they were interested in further training, especially training that is focused on their specific needs. Such training should include practical examples of how to implement changes in food and physical activity environments, as well as motivational examples of successful changes in FCCHs with compelling role models. These trainings should also educate providers on responsive feeding practices and how they could involve children in food preparation and education.

Our study has limitations. First, we used self-reported data, which were not validated and may have been influenced by socially desirable responses. However, this bias would have affected the entire sample and would not explain the ethnic differences we observed. A few studies have addressed the issues of self-report and social desirability bias by direct observation of child-care practices; this approach is more objective but time-consuming and cost-intensive. Second, providers who did not respond to the survey despite many attempts may have represented a more time- or resource-constrained group, and those we did reach may have been more health-conscious, which may have introduced selection bias. However, the high proportion of FCCHs reached ( $43 \%$ of those randomly chosen and eligible) indicates that this bias is likely small. Finally, we did not have data on child race/ethnicity and income; rather, participation in CACFP was used as a proxy indicator of socioeconomic status of the provider and children being served.

In conclusion, we found that, although positive practices exist in the FCCHs surveyed, there is room for improvement. It is important for FCCHs to follow practices that are consistent with the 2011 national recommendations for child-care policies and practices to reduce childhood obesity (36). Rhode Island recently proposed strengthening its regulations for child-care centers and FCCHs (including health and nutrition) (14), although these regulations are still under review. However, even if such policies and regulations are strengthened, FCCH providers are unlikely to follow them without adequate training and resources. Our findings will inform the development of new trainings that incorporate information of the recently proposed regulations. These trainings can also be enhanced to include information on responsive feeding and parent communication and ensure that they are culturally and linguistically appropriate for ethnically diverse FCCH providers. Our res-

\footnotetext{
The opinions expressed by authors contributing to this journal do not necessarily reflect the opinions of the U.S. Department of Health and Human Services, the Public Health Service, the Centers for Disease Control and Prevention, or the authors' affiliated institutions.
} 
ults will be communicated to state and local agencies and organizations such as the Department of Children, Youth and Families; Rhode Island Department of Education; the Center for Early Learning Professionals; and Ready to Learn Providence to enable such stakeholders to work together to translate policies, regulations, or quality rating systems into practical and effective trainings that are appropriate for different racial and ethnic groups.

\section{Acknowledgments}

We thank Heather Butler Feliz and Emma Lamothe who collected the data and initiated the data analysis. This study was funded by cooperative agreement no. 5U58DP001385 from Centers for Disease Control and Prevention, awarded to the Rhode Island Department of Health.

\section{Author Information}

Corresponding Author: Alison Tovar, PhD, MPH, Department of Nutrition and Food Sciences, University of Rhode Island, Kingston, Rhode Island 02881. Telephone: 401-874-9855. Email: alison_tovar@mail.uri.edu.

Author Affiliations: Patricia Risica, Kim M. Gans, Institute for Community Health Promotion, Brown University School of Public Health, Providence, Rhode Island, and Human Development and Family Studies Department and Center for Health, Intervention, and Prevention, University of Connecticut, Storrs, Connecticut; Noereem Mena, Department of Nutrition and Food Sciences, University of Rhode Island, Kingston, Rhode Island; Eliza Lawson, Chronic Disease Prevention and Control Initiative, Rhode Island Department of Health, Providence, Rhode Island; Angela Ankoma, Office of Minority Health, Rhode Island Department of Health, Providence, Rhode Island.

\section{References}

1. Ogden CL, Carroll MD, Kit BK, Flegal KM. Prevalence of childhood and adult obesity in the United States, 2011-2012. JAMA 2014;311(8):806-14.

2. Ogata BN, Hayes D. Position of the Academy of Nutrition and Dietetics: nutrition guidance for healthy children ages 2 to 11 years. J Acad Nutr Diet 2014;114(8):1257-76.

3. Skinner JD, Carruth BR, Bounds W, Ziegler PJ. Children's food preferences: a longitudinal analysis. J Am Diet Assoc 2002;102(11):1638-47.
4. Brennan L, Castro S, Brownson RC, Claus J, Orleans CT. Accelerating evidence reviews and broadening evidence standards to identify effective, promising, and emerging policy and environmental strategies for prevention of childhood obesity. Annu Rev Public Health 2011;32(1):199-223.

5. Percentage distribution of children at about 4 years of age, by primary type of child care arrangement and selected characteristics: 2005-06. Washington (DC): US Department of Education, National Center for Education Statistics; 2012.

6. Sigman-Grant M, Christiansen E, Fernandez G, Fletcher J, Johnson SL, Branen L, et al. Child care provider training and a supportive feeding environment in child care settings in 4 states, 2003. Prev Chronic Dis 2011;8(5):A113.

7. Larson N, Ward DS, Neelon SB, Story M. What role can childcare settings play in obesity prevention? A review of the evidence and call for research efforts. J Am Diet Assoc 2011; 111(9):1343-62.

8. Children under age 6 in family-based childcare (Percent), 2007. In: Kids Count. Baltimore (MD): The Annie E. Casey Foundation; 2007.

9. Benjamin SE, Taveras EM, Cradock AL, Walker EM, Slining MM, Gillman MW. State and regional variation in regulations related to feeding infants in child care. Pediatrics 2009; 124(1):e104-11.

10. Benjamin SE, Rifas-Shiman SL, Taveras EM, Haines J, Finkelstein J, Kleinman K, et al. Early child care and adiposity at ages 1 and 3 years. Pediatrics 2009;124(2):555-62.

11. Ammerman AS, Benjamin SE, Sommers JK, Ward DS. The Nutrition and Physical Activity Self-Assessment for Child Care (NAP SACC) environmental self-assessment instrument. Chapel Hill (NC): Center for Health Promotion and Disease Prevention, University of North Carolina at Chapel Hill; 2004. Revised May 2007.

12. California childcare food assessment: survey of child care providers of 2-5 year old children. Berkeley (CA): Center for Weight and Health, University of California, Berkeley; 2008.

13. Enev T. Delaware child care providers survey. Newark (DE): Nemours Health and Prevention Services; 2009.

14. Bright Stars Rhode Island. http://www.brightstars.org.

15. Natale RA, Messiah SE, Asfour L, Uhlhorn SB, Delamater A, Arheart KL. Role modeling as an early childhood obesity prevention strategy: effect of parents and teachers on preschool children's healthy lifestyle habits. J Dev Behav Pediatr 2014; 35(6):378-87.

16. Birch LL. Development of food preferences. Annu Rev Nutr 1999;19(1):41-62.

The opinions expressed by authors contributing to this journal do not necessarily reflect the opinions of the U.S. Department of Health and Human Services, the Public Health Service, the Centers for Disease Control and Prevention, or the authors' affiliated institutions. 
17. Rosenthal MS, Crowley AA, Curry L. Family child care providers' self-perceived role in obesity prevention: working with children, parents, and external influences. J Nutr Educ Behav 2013;45(6):595-601.

18. Dixon B, Peña MM, Taveras EM. Lifecourse approach to racial/ethnic disparities in childhood obesity. Adv Nutr 2012; 3(1):73-82.

19. Hughes SO, Anderson CB, Power TG, Micheli N, Jaramillo S, Nicklas TA. Measuring feeding in low-income AfricanAmerican and Hispanic parents. Appetite 2006;46(2):215-23.

20. Porter T, Paulsell D, Del Grosso P, Avellar S, Hass R, Vuong L. A review of the literature on home-based child care: implications for future directions. Washington (DC): Administration for Children and Families; 2010.

21. Freedman MR, Alvarez KP. Early childhood feeding: assessing knowledge, attitude, and practices of multi-ethnic child-care providers. J Am Diet Assoc 2010;110(3):447-51.

22. Alkon A, Crowley AA, Neelon SE, Hill S, Pan Y, Nguyen V, et al. Nutrition and physical activity randomized control trial in child care centers improves knowledge, policies, and children's body mass index. BMC Public Health 2014;14(1):215.

23. Gallo LC, Penedo FJ, Espinosa de los Monteros K, Arguelles W. Resiliency in the face of disadvantage: do Hispanic cultural characteristics protect health outcomes? J Pers 2009; 77(6):1707-46.

24. Intagliata V, Ip EH, Gesell SB, Barkin SL. Accuracy of selfand parental perception of overweight among Latino preadolescents. N C Med J 2008;69(2):88-91.

25. Crawford PB, Gosliner W, Anderson C, Strode P, BecerraJones Y, Samuels S, et al. Counseling Latina mothers of preschool children about weight issues: suggestions for a new framework. J Am Diet Assoc 2004;104(3):387-94.

26. Tucker P, van Zandvoort MM, Burke SM, Irwin JD. The influence of parents and the home environment on preschoolers' physical activity behaviours: a qualitative investigation of childcare providers' perspectives. BMC Public Health 2011;11(1):168.

27. Benjamin Neelon SE, Briley ME;American Dietetic Association. Position of the American Dietetic Association: benchmarks for nutrition in child care. J Am Diet Assoc 2011; 111(4):607-15.

28. Gubbels JS, Van Kann DH, de Vries NK, Thijs C, Kremers SP. The next step in health behavior research: the need for ecological moderation analyses - an application to diet and physical activity at childcare. Int J Behav Nutr Phys Act 2014; 11(1):52.
29. Natale RA, Lopez-Mitnik G, Uhlhorn SB, Asfour L, Messiah SE. Effect of a child care center-based obesity prevention program on body mass index and nutrition practices among preschool-aged children. Health Promot Pract 2014; 15(5):695-705.

30. Spectrum for opportunities for obesity prevention in the early care and education setting (EDC). CDC Technical Assistance Briefing Document. Atlanta (GA): Centers for Disease Control and Prevention.

31. Buscemi JK, Becker AB, Ward DS, Fitzgibbon ML. Society of Behavioral Medicine position statement: Early Care and Education (ECE) policies can impact obesity prevention among preschool aged children. Milwaukee (WI): Society of Behavioral Medicine; 2014.

32. Early childhood obesity prevention policies. Washington (DC): Institute of Medicine; 2011.

33. Blanck HM, Kim SA. Creating supportive nutrition environments for population health impact and health equity: an overview of the Nutrition and Obesity Policy Research and Evaluation Network's efforts. Am J Prev Med 2012;43(3, Suppl 2):S85-90.

34. Weaver R. Predicators of quality and commitment in family child care: provider education, personal resources, and support. Early Educ Dev 2002;13(3).

35. Trost SG, Messner L, Fitzgerald K, Roths B. A nutrition and physical activity intervention for family child care homes. Am J Prev Med 2011;41(4):392-8.

36. Institute of Medicine. Early childhood obesity prevention policies. Washington (DC): The National Academies Press; 2011.

\footnotetext{
The opinions expressed by authors contributing to this journal do not necessarily reflect the opinions of the U.S. Department of Health and Human Services, the Public Health Service, the Centers for Disease Control and Prevention, or the authors' affiliated institutions.
} 


\section{Table}

Table. Provider Responses Related to Nutrition Training, Feeding Practices, and Attitudes About Parent Involvement

\begin{tabular}{|c|c|c|c|c|c|c|c|c|c|c|c|c|c|c|}
\hline Question & \multicolumn{4}{|c|}{ All Providers, \% } & \multicolumn{4}{|c|}{$\begin{array}{l}\text { Non-Hispanic } \\
\text { Providers, \% }\end{array}$} & \multicolumn{4}{|c|}{ Hispanic Providers, \% } & $\begin{array}{l}\text { Hispanic, } \\
\text { Crude }\end{array}$ & $\begin{array}{l}\text { Hispanic, } \\
\text { Adjusted for } \\
\text { CACFP }\end{array}$ \\
\hline \multicolumn{15}{|c|}{ Nutrition Training } \\
\hline No. of times & \multicolumn{2}{|c|}{$0-3$} & \multicolumn{2}{|c|}{$4-7$} & \multicolumn{2}{|c|}{$0-3$} & \multicolumn{2}{|c|}{ 4-7 } & \multicolumn{2}{|c|}{$0-3$} & \multicolumn{2}{|c|}{$4-7$} & $\beta(P)$ & $\beta(P)$ \\
\hline $\begin{array}{l}\text { How often have you received } \\
\text { training on nutrition in the } \\
\text { past } 3 \text { years? }\end{array}$ & \multicolumn{2}{|r|}{67.6} & \multicolumn{2}{|r|}{32.4} & \multicolumn{2}{|r|}{76.2} & \multicolumn{2}{|r|}{23.8} & \multicolumn{2}{|r|}{53.9} & \multicolumn{2}{|r|}{46.2} & $-1.0(.02)$ & $-1.1(.02)$ \\
\hline $\begin{array}{l}\text { How helpful did you find the } \\
\text { class(es)? }\end{array}$ & \multicolumn{2}{|c|}{35.2} & \multicolumn{2}{|c|}{64.8} & \multicolumn{2}{|c|}{54.9} & \multicolumn{2}{|c|}{45.1} & \multicolumn{2}{|r|}{8.1} & \multicolumn{2}{|c|}{91.9} & $\begin{array}{r}-2.6 \\
(<.001) \\
\end{array}$ & $-2.4(<.001)$ \\
\hline $\begin{array}{l}\text { How helpful do you think it } \\
\text { would be to have more } \\
\text { training focused on home } \\
\text { based child-care programs? }\end{array}$ & \multicolumn{2}{|r|}{42.4} & \multicolumn{2}{|r|}{57.6} & \multicolumn{2}{|r|}{63.8} & \multicolumn{2}{|r|}{36.2} & & 12.2 & & 87.8 & $(<.001)$ & $-2.5(<.001)$ \\
\hline & & & & & ovider I & Feedin & g Prac & tices $^{a}$ & & & & & & \\
\hline $\begin{array}{l}\text { I sit with the children during } \\
\text { snacks and meals. }\end{array}$ & 67.3 & 29.8 & 1.0 & 1.9 & 59.4 & 35.9 & 1.6 & 3.1 & 80.0 & 20.0 & 0 & 0 & $-1.0(.03)$ & $-1.1(.02)$ \\
\hline $\begin{array}{l}\text { I rarely eat the same foods } \\
\text { and have the same drinks } \\
\text { as the children. }\end{array}$ & 9.8 & 24.5 & 40.2 & 25.5 & 6.4 & 33.3 & 39.7 & 20.6 & 15.4 & 10.3 & 41.0 & 33.3 & $-0.46(.22)$ & $-0.65(.11)$ \\
\hline $\begin{array}{l}\text { I am highly motivated to } \\
\text { serve healthy foods to the } \\
\text { children. }\end{array}$ & 71.8 & 28.2 & - & - & 58.7 & 41.3 & - & - & 92.5 & 7.5 & - & - & $2.2(.001)$ & $1.9(.006)$ \\
\hline $\begin{array}{l}\text { Children are encouraged to } \\
\text { finish the food on their plate. }\end{array}$ & 38.8 & 35.9 & 18.5 & 6.8 & 12.7 & 49.2 & 28.6 & 9.5 & 80.0 & 15.0 & 2.5 & 2.5 & $\begin{array}{r}-3.3 \\
(<.001) \\
\end{array}$ & $-3.1(<.001)$ \\
\hline $\begin{array}{l}\text { Children like to try new } \\
\text { foods. }\end{array}$ & 19.8 & 53.5 & 18.8 & 7.9 & 15.9 & 46.0 & 25.4 & 12.7 & 26.3 & 65.8 & 7.9 & 0 & $-0.64(.21)$ & $-0.5(.30)$ \\
\hline & & & Attitu & ides $A$ & bout $\mathrm{Pa}$ & arents/ & Paren & t Involv & vement & & & & & \\
\hline $\begin{array}{l}\text { Parents/families demand } \\
\text { that their children be served } \\
\text { healthy foods. }\end{array}$ & 22.8 & 45.5 & 21.8 & 9.9 & 9.7 & 53.2 & 25.8 & 11.3 & 43.6 & 33.3 & 15.4 & 7.7 & $0.68(.14)$ & $0.66(.17)$ \\
\hline From conversations with & 18.2 & 58.6 & 19.2 & 4.0 & 12.5 & 60.9 & 20.3 & 6.3 & 28.6 & 54.3 & 17.1 & 0 & $0.56(.29)$ & $0.24(.66)$ \\
\hline
\end{tabular}

Abbreviations: A, agree; CACFP, Child and Adult Care Food Program; D, disagree; N/S, not/somewhat; SA, strongly agree; SD, strongly disagree.

a Response options for some variables were collapsed because of small numbers; more information about collapsing of variables can be obtained from the corresponding author.

(continued on next page)

The opinions expressed by authors contributing to this journal do not necessarily reflect the opinions of the U.S. Department of Health and Human Services, the Public Health Service, the Centers for Disease Control and Prevention, or the authors' affiliated institutions. 
(continued)

Table. Provider Responses Related to Nutrition Training, Feeding Practices, and Attitudes About Parent Involvement

\begin{tabular}{|c|c|c|c|c|c|c|c|c|c|c|c|c|c|c|}
\hline \multirow[b]{2}{*}{$\begin{array}{l}\text { parents/families and } \\
\text { children, it seems that } \\
\text { parents know about healthy } \\
\text { foods to serve to children. }\end{array}$} & \multicolumn{4}{|c|}{ All Providers, \% } & \multicolumn{4}{|c|}{$\begin{array}{l}\text { Non-Hispanic } \\
\text { Providers, \% }\end{array}$} & \multicolumn{4}{|c|}{ Hispanic Providers, \% } & \multirow[t]{2}{*}{$\begin{array}{l}\text { Hispanic, } \\
\text { Crude }\end{array}$} & \multirow[t]{2}{*}{$\begin{array}{l}\text { Hispanic, } \\
\text { Adjusted for } \\
\text { CACFP }\end{array}$} \\
\hline & & & & & & & & & & & & & & \\
\hline $\begin{array}{l}\text { From conversations with } \\
\text { parents/families and } \\
\text { children, it seems that } \\
\text { parents reinforce nutrition } \\
\text { education at home. }\end{array}$ & 10.3 & 52.6 & 28.9 & 8.3 & 5.0 & 56.7 & 28.3 & 10.0 & 18.9 & 46.0 & 29.7 & 5.4 & $0.14(.75)$ & $0.09(.84)$ \\
\hline $\begin{array}{l}\text { It seems that parents/ } \\
\text { families are concerned } \\
\text { about the quality of fruits } \\
\text { and vegetables. }\end{array}$ & 16.0 & 50.0 & 24.5 & 9.6 & 6.9 & 51.7 & 27.6 & 13.8 & 30.6 & 47.2 & 19.4 & 2.8 & $0.9(.06)$ & $0.86(.09)$ \\
\hline $\begin{array}{l}\text { Parents/families regularly } \\
\text { ask what their child has } \\
\text { eaten. }\end{array}$ & 27.7 & 45.5 & 20.8 & 5.9 & 20.6 & 47.6 & 23.8 & 7.9 & 39.5 & 42.1 & 15.8 & 2.6 & $0.72(.15)$ & $0.43(.42)$ \\
\hline $\begin{array}{l}\text { A parent has stated that } \\
\text { their children will eat certain } \\
\text { foods at daycare and not at } \\
\text { home. }\end{array}$ & 40.4 & 38.4 & 14.1 & 7.1 & 42.9 & 46.0 & 4.8 & 6.4 & 36.1 & 25.0 & 30.6 & 8.3 & $-1.6(.002)$ & $-1.5(.005)$ \\
\hline $\begin{array}{l}\text { I believe it is important to } \\
\text { communicate with parents/ } \\
\text { families regarding nutrition. }\end{array}$ & 63.5 & 31.7 & 4.8 & - & 47.6 & 46.0 & 6.3 & - & 87.8 & 9.8 & 2.4 & - & $(<.001)$ & $-1.5(.003)$ \\
\hline $\begin{array}{l}\text { I discuss with parents/ } \\
\text { families if lunches or snacks } \\
\text { sent in are not healthy }\end{array}$ & 38.9 & 41.1 & 16.7 & 3.3 & 20.4 & 50.0 & 24.0 & 5.6 & 66.7 & 27.8 & 5.6 & 0 & $-1.3(.001)$ & $-1.3(<.001)$ \\
\hline $\begin{array}{l}\text { I am comfortable } \\
\text { encouraging parents/ } \\
\text { families to breastfeed their } \\
\text { infants. }\end{array}$ & 67.8 & 20.0 & 7.8 & 4.4 & 59.6 & 19.2 & 13.5 & 7.7 & 79.0 & 21.0 & 0 & 0 & $1.2(.003)$ & $1.2(.008)$ \\
\hline $\begin{array}{l}\text { I am comfortable discussing } \\
\text { a child's weight problem } \\
\text { with parents/families. }\end{array}$ & 36.5 & 37.5 & 20.8 & 5.2 & 22.8 & 36.8 & 31.6 & 8.8 & 56.4 & 38.5 & 5.1 & 0 & $0.74(.05)$ & $0.59(.12)$ \\
\hline
\end{tabular}

Abbreviations: A, agree; CACFP, Child and Adult Care Food Program; D, disagree; N/S, not/somewhat; SA, strongly agree; SD, strongly disagree.

a Response options for some variables were collapsed because of small numbers; more information about collapsing of variables can be obtained from the corresponding author.

The opinions expressed by authors contributing to this journal do not necessarily reflect the opinions of the U.S. Department of Health and Human Services, the Public Health Service, the Centers for Disease Control and Prevention, or the authors' affiliated institutions. 